\title{
Lipid Peroxidation System in Women and their Newborns after Consuming Small Amounts of Alcohol during Pregnancy
}

\author{
${ }^{1}$ Federal State Public Scientific Institution, Russia \\ ${ }^{2}$ University of Oklahoma Health Sciences Center, USA \\ ${ }^{3}$ Irkutsk State Medical Academy of Postgraduate Education, Russia \\ ${ }^{4}$ Lomonosov Moscow State University, Russia
}

Lubov Kolesnikova ${ }^{1 *}$, Sergei Kolesnikovad ${ }^{4}$, Anait Marianian${ }^{1}$, Yui Yamaoka ${ }^{2}$, Marina Darenskaya' ${ }^{1}$, Lyudmila Grebenkina ${ }^{1}$, Natalia Protopopova ${ }^{3}$, Mary Stockett ${ }^{2}$ and Tatiana Balachova ${ }^{2}$

Submission: November 29, 2017 ; Published: January 05, 2018

*Corresponding author: Lubov Kolesnikova, Federal State Public Scientific Institution "Scientific Centre for Family Health and Human Reproduction Problems", (SC FHHRP), Irkutsk, Russia, Email: anait_24@mail.ru

\section{Mini Review}

It is common knowledge that a fetus is exposed to the decay products of alcohol in the mother-fetus blood circulation system and this exposure disorganizes the entire metabolism system. It enhances the action of other harmful factors on the fetus, including provoking the development of hereditary diseases. Alcohol abuse during pregnancy is dangerous not only for mother but also for fetus. The period of organogenesis in embryonic development is critical in terms of the long-term effects of alcohol exposure. One of the reasons of alcohol teratogenic effect is its rapid penetration through the placenta and blood-brain barrier. Because of that, alcohol can cause more serious effects than many other substances, including maternal smoking and illicit drug use [1-5]. As shown in numerous studies, even in small doses of ethanol and its metabolites, especially acetaldehyde, lead to congenital malformations of the child, directly or indirectly through disruption of maternal biochemical mechanisms, and result sometime in fetal alcohol syndrome $[6,7]$.

In our study, a beverage-specific approach was used to determine standardized alcohol content and volume of alcohol consumption. Participants were provided with a card that showed pictures of alcoholic beverages and containers that are common in Russia, and were asked about the type of beverage, type of container, and number of containers consumed during each month of pregnancy. This information was transformed into ethanol volume. The total amounts of alcohol consumed during the pregnancy first half (1-20 weeks of gestation) and the second half (21-40 weeks) calculated for each participant and utilized in data analysis. For reporting clarity, these data were then transformed to U.S. standard drink units (i.e., 14 grams of pure alcohol) [6]. Women were categorized as having very low alcohol consumption ( $n=75$, Group 2) if during this period they drank less than 3,85U.S. standard drink units of beer, dry wine, or champagne, and categorized as having low alcohol consumption ( $\mathrm{n}=33$, Group 3$)$ if they consumed 3,85 and up to 19 U.S. standard drink units of beer, dry wine, or champagne. The control group was women who did not consumed alcohol during pregnancy (Group 1). This study followed the ethical principles requirements of the Helsinki Declaration of the World Medical Association. All participants provided informed consent for their and their infants' participation in the study.

Our findings indicate that even a small amount of alcohol consumed during pregnancy can cause serious metabolic changes in mothers. In particular, alcohol exposure leads to an imbalance of redox exchange and dysfunction of the "lipid peroxidationantioxidant defense" (LPO-AOD) system. The concentrations of thiobarbituric acid reactants (TBAR) $60.4 \%$ higher in the very low and low drinking groups than in the control group of non-drinkers. The increase of TBARs indicates the decline of antioxidant defence that can be described as the development of oxidative stress [8].

Retinol concentration decreased in both drinking groups compared with the control group. This reduction may result in a corresponding reduction in the antioxidant effect of retinol. The role of retinol as a prohormone may also be affected by oxidation, prompting its development into retinoic acid, a true hormone, that is involved in regulation of gene expression $[9,10]$. Further, retinoic acid has morphogenetic action, and its deficiency can lead to fetal malformations. 
Superoxide dismutase activity was significantly lower in very low drinkers than in non-drinkers. Because of the high content of the enzyme in the red blood cell even a small reduction in super oxide dismutase (SOD) activity is an important signal of the metabolic shift in the direction of prevailing pro-oxidant processes [9]. Women who drank very low amounts of alcohol had lower GSH (reduced glutathione) and GR (glutathione reductase activity) values, and higher oxidized glutathione (GSSG) and glutathione-S-transferase activity (GST) levels, compared to those who drank no alcohol. The reduced form of glutathione participates in the neutralization of oxidants and in the transport of substances across membranes, and has an antitoxic effect. The decreased GSH and GR levels in women who consumed alcoholic beverages had a negative effect on women's health. Reduced activity of GR in women who consumed even very low doses of alcohol, in turn, indicates the protective function of the enzyme, conversion of oxidized glutathione to reduced glutathione.

Infants prenatally exposed to small and moderate amounts of alcohol had higher rates of pathological conditions, smaller heights and weights, larger fontanelles, and smaller head circumferences at birth and 6 and 12 months of age, as well as delayed psychomotor development compared with those who did not exposed to alcohol and it metabolites during pregnancy. The LPO-AOD system changes in newborns were like those occurred in their mothers, especially for SOD, GSH, and GR. The decrease in GSH concentration and activity of the enzymes involved in its metabolism, which were found in infants of Group 2, has a negative effect on the balance in the LPO-AOD system. Because $\alpha$-tocopherol involved in glutathione biosynthesis regulation, in this case, $\alpha$-tocopherol has an indirect effect on the antioxidant defence system [10].

The LPO-AOD system assessments in women who consumed even low doses of alcoholic beverages during pregnancy revealed signs of increased oxidative stress. Thus, we suggest that this can cause serious metabolic changes in the newborn baby, leading to an imbalance of redox exchange and dysfunction of the LPO-AOD system.

Dysfunction of the LPO-AOD system and development of oxidative stress can have negative effects on infant growth, health, and development. It is a strong message to specialists in the medical and social care to prevent any amount of alcohol consumption in pregnant women.

\section{References}

1. Malachova J, Shilko V, Bubnov A (2012) Fetal alcohol syndrome in infants. Lambert Academic Publishing, Russia, pp. 164.

2. Randall CL (2001) Alcohol and pregnancy: Highlights from three decades of research. J Stud Alcohol 62(5): 554-561.

3. Riley EP, McGee CL (2005) Fetal alcohol spectrum disorders: An overview with emphasis on changes in brain and behavior. Exp Biol Med Maywood 230(6): 357-365.

4. Shilko V (2011) Fetal alcohol syndrome: Clinical and pathogenetic characteristic effects in young children. Urals State Medical Academy, Ecaterinburg, Russia.

5. Thackray H, Tifft C (2001) Fetal alcohol syndrome. Pediatr Rev 22: 4755.

6. Balachova T, Bonner B, Chaffin M, Bard D, Isurina G, et al. (2012) Women's alcohol consumption and risk for alcohol-exposed pregnancies in Russia. Addiction 107(1): 109-117.

7. Popova S, Lange S, Probst Ch, Gmel G, Rehm J (2017) Estimation of national, regional, and global prevalence of alcohol use during pregnancy and fetal alcohol syndrome: a systematic review and metaanalysis. The Lancet Global Health 5(3): e290-e299.

8. Kolesnikova L, Osipova E, Grebyonkina L (2011) Oxidative stress in reproductive endocrine disorders in women genesis. Science: Novosibirsk pp. 116.

9. Kolesnikova L, Grebyonkina L, Darenskaya M, Vlasov BJ (2012) Oxidative stress as a nonspecific pathogenic link of reproductive disorders (review). Siberian Journal of Medical Research 1: 58-66.

10. Townsend DM, Tew KD, Tapiero H (2003) The importance of glutathione in human disease. Biomed Pharmacother 57(3-4): 145-155.

\section{Your next submission with Juniper Publishers} will reach you the below assets

- Quality Editorial service

- Swift Peer Review

- Reprints availability

- E-prints Service

- Manuscript Podcast for convenient understanding

- Global attainment for your research

- Manuscript accessibility in different formats

( Pdf, E-pub, Full Text, Audio)

- Unceasing customer service

Track the below URL for one-step submission https://juniperpublishers.com/online-submission.php 